\title{
Application of Computer Assisted Instruction in Teaching of Mechanisms and Machine Theory Course
}

\author{
Bo Tang \\ School of Machinery and Automation \\ Wuhan University of Science and Technology \\ Wuhan, China \\ tang1017@163.com \\ Guangming Zou \\ School of Machinery and Automation \\ Wuhan University of Science and Technology \\ Wuhan, China \\ zougm2000@163.com
}

\author{
Yu Hou \\ School of Machinery and Automation \\ Wuhan University of Science and Technology \\ Wuhan, China \\ fly_houyu@163.com \\ Huaiguang Liu \\ School of Machinery and Automation \\ Wuhan University of Science and Technology \\ Wuhan, China \\ lhg81219@163.com
}

\begin{abstract}
In order to enable students to better grasp mechanisms and machine theory course, teachers can use various forms of computer assisted instruction in the teaching process. The importance of computer aided instruction in the teaching of mechanisms and machine theory course is explained, and the principles and means of computer assisted instruction are discussed, and the ways of applying computer technology in the course is carried out. Computer technology has been fully used in the course of mechanisms and machine theory course, which improves the students' interest in learning, and strengthens the learning effect, and then improves the comprehensive quality of students. The innovation of this paper lies in the use of modern educational theory and modern teaching methods and means, the relationship and rules of classroom teaching and experimental teaching of mechanical principle course, and computer assisted instruction into the whole teaching process to cultivate students' autonomous learning ability and knowledge application ability, practical ability etc.
\end{abstract}

Keywords-mechanisms and machine theory course; computer aided instruction;engineering application software component

\section{INTRODUCTION}

Mechanisms and machine theory course is an important basic technical course for engineering mechanical majors in colleges and universities, which gives lectures on the kinematics, mechanical dynamics and mechanical system design of the mechanism. The and machine theory course trains the thinking mode and method of the innovative design of the mechanical system scheme, and the comprehensive design ability, innovative design ability and engineering practice ability of the mechanical system scheme. In the overall situation of cultivating students' comprehensive design ability, mechanisms and machine theory course occupies a very important position in the curriculum system [1].
Mechanisms and machine theory course has typical theoretical, comprehensive and practical characteristics. The salient feature of the subject is that the contents of education are abstract and not easy to understand. In order to make students better understand the contents of the course, teacher can introduce the ways of computer assisted instruction in the teaching process. The combination of modern design method and computer software with mechanisms and machine theory will be in great need for engineering college students. Computer aided instruction software include 3D drawing software (SOLIDWORKS, PRO/E or UG), computer programming software VC++, VB or DELPHI, calculation and analysis software MATLAB and dynamic simulation software ADAMS, etc.

\section{PRINCIPLES AND MEANS OF COMPUTER ASSISTED INSTRUCTION}

\section{A. Principles of Computer Assisted Instruction}

There are many ways to apply computer aided instruction in the course of Mechanisms and machine theory course. The principle is the combination of classroom and extracurricular, the combination of theory and practice, the combination of self-programming and the application of existing software.

Teachers in the classroom to guide the application of computer assisted instruction, combined with specific examples for explanation and demonstration. Then, the students learn these software outside the classroom, and teachers assign a certain task for students to complete. In this way, students will be familiar with the application of software and can be stimulated their learning interest.

The practical teaching of mechanisms and machine theory course also occupies a very important position. The forms of practice teaching are varied, including experiment, comprehensive homework, curriculum design and 
extracurricular competition activities. All of these practical links can be applied to computer assisted instruction, and often will play a good effect.

Computer aided instruction in mechanisms and machine theory course should be based on the relevant theoretical knowledge of mechanisms and machine theory course, and then combine with computer software to practice and consolidate the theoretical knowledge.

\section{B. Means of Computer Assisted Instruction}

\section{1) Application of visual software}

Mechanisms and machine theory course is a course with strong theory and practice. According to different teaching contents, computer technology can be applied in many perspectives.

In order to clarify the complex structure of the machine, such as internal combustion engines, jaw crusher, gearbox, differential mechanism, flying shear mechanism, rolling machinery, teacher can let the students be familiar with the structure and based on the basic principle, using 3D modeling software PRO/E, SOLIDWORKS, UG or 3D MAX, which shows mechanical system in the multi angle ways.

Virtual prototype is a computer model, which can reflect the characteristics of actual products, including appearance, spatial relations, kinematics and dynamics. The use of virtual prototyping technology, visualization model can quickly establish the mechanical system with computer. The kinematic and dynamic characteristics of the mechanical system are simulated and optimized according to the simulation results.

ADAMS is the most widely used mechanical system kinematics and dynamics simulation analysis software. Users can use this software to conveniently carry out statics, kinematics and dynamics analysis of the virtual prototype. The structure and motion of the cam mechanism, gear mechanism, linkage mechanism and other commonly used conveniently displayed by ADAMS software. At the same time, the ADAMS software can be used to simulate the statics, kinematics and dynamics of the mechanical system, and optimize the mechanical system according to the results of the simulation analysis, and obtain the optimal design scheme [2].

\section{2) Non visual data analysis and processing}

Non visual data analysis and processing is mainly based on the existing data processing software (such as MATLAB) to establish the mathematical model of the mechanism and the results are expressed in numerical or curvilinear form through calculation.

The typical applications are as follows. According to Newton mechanics and vector method, the kinematic and dynamic equations of the mechanism are established, and the dynamics simulation is carried out by using SIMULINK to solve the reaction force and the balance torque of the mechanism [3]. Optimization design of mechanism based on MATLAB optimization toolbox function can be carried out. With the powerful numerical calculation, programming and drawing function of MATLAB, the kinematic equation of cam mechanism is established. The contour curve of cam mechanism is obtained by using MATLAB programming, and the motion law of follower is also analyzed.

\section{3) Self compiled computer program}

On the basis of mastering the relevant theory knowledge of mechanisms and machine theory course, the visual software is compiled by using VC++, VB or DELPHI platform to realize the kinematics analysis and dynamics analysis of the mechanism. For example, the motion trajectory, position analysis, velocity (angular velocity) analysis and acceleration (angular acceleration) of the linkage mechanism are analyzed by self-compiled software, and the results are shown with curves and charts. It can also use ActiveX technology, making full use of the advantages of MATLAB software and VB software, and then write software with good man-machine interface [4]. It not only makes the students deepen the theoretical knowledge, but also let the students master the programming of the computer program and the application of the software.

The above three methods have their own characteristics and complement each other, forming a unified organic whole of computer assisted instruction, and can be flexibly used in combination with specific tasks. The first method requires students to be very proficient in visualization software, and the software has strong interactivity. The analysis results are relatively reliable and suitable for the analysis and calculation of complex mechanical systems. The second methods require students to have a good foundation for the knowledge of mechanisms and machine theory course, and have a certain programming ability, suitable for the analysis of simple mechanism. The third methods require students to have high level of computer programming and rich knowledge of mechanisms and machine theory course; it is a comprehensive training for students, but it is limited to the analysis and calculation of complex mechanical systems [5].

\section{THE WAYS OF COMPUTER ASSISTED INSTRUCTION}

\section{A. Theoretical Teaching and Practical Teaching}

Synchronized with the course teaching, 3D modeling software PRO/E, SOLIDWORKS or UG was used to demonstrate the 3D model and motion simulation of complex mechanical systems such as internal combustion engine, crusher and robot. Using $\mathrm{VB}, \mathrm{VC}++$ or DELPHI get the displacement mechanism of different scales (angular displacement), speed (angular velocity) and acceleration (acceleration), and compare with the theoretical calculation. The iterative algorithm, linearization method and optimization algorithm used in mechanism analysis and design are implemented by MATLAB. Kinematics and dynamics analysis and calculation of mechanical system are carried out by ADAMS.

Synchronized with the experimental teaching, the software to play the demonstration method for involutes gear, undercutting phenomenon, similarities and differences between the standard gear and gear demonstration; at the same time through the computer simulation of the motion of the mechanism and ADAMS mechanism based on virtual experimental design, so as to realize the computer assisted instruction. 


\section{B. Curriculum Design}

Curriculum design should face the real life and face the frontier of science and technology. Mechanisms closely related to lives such as food mixer, pencil sharpener, folding chairs, adjustable lamp, electric fan, umbrella frame, auto transmission, camera shutter; machinery in the frontier of science and technology such as 3D printing, controlled five bar mechanism, robot, and space station mechanism, all of these can be used as the object of curriculum design.

In the curriculum design, the motion analysis and parameter design should be carried out after each mechanism scheme is determined. The trajectory of the mechanism, the displacement, velocity and acceleration of the key points are obtained by the analytical method and the numerical method. The calculation of the practical application of the project can well train the students' scientific computing ability.

Students' manual calculation can only realize the motion analysis of the limited position of the mechanism. With the help of the common engineering software, the modeling and simulation analysis of the mechanism can achieve higher efficiency. For example, the use of three-dimensional drawing software SOLIDWORKS, PRO/E or UG and other modeling, simulation analysis in ADAMS, thus cultivate students' software application ability [6].

\section{Comprehensive Homework}

Students observe various institutions in practice, such as car door opening mechanism, port crane, crusher, packing machine, printer, pencil sharpener, window opening mechanism, clamping mechanism, locking mechanism, etc.. The students select one of them to draw the kinematic sketch of the mechanism, and analyze the rationality of the composition and structure of the mechanism. It is required to write analytical thinking, and draw calculation flow chart, and then write calculation program, thus analyze existing problems and causes, at last propose improvement methods. It is the effect way to cultivate students' analytical and computational ability.

In addition, the innovative design of the mechanism is carried out according to the given functional requirements. The mechanism model is established by ADAMS and its motion and dynamic characteristics are analyzed, and its feasibility is tested. It is the effect way to cultivate students' ability of thinking and innovation.

\section{Mechanical Innovation Design Competition}

The purpose of mechanical innovation design competition for college students is to improve the design ability and cooperation spirit of college students, and strengthen the cultivation of students' practical ability, and improve the practical work ability of mechanical innovation design and production. Encouraging students to participate in extracurricular scientific and technological activities, so as to cultivate excellent talents

According to the theme of the competition, students use the mechanism analysis and simulation software for virtual design and motion simulation, and optimize the structural parameters of the mechanism, and then make the physical model according to the optimal results. In the mechanical innovation design competition for college students, computer aided means are often indispensable.

\section{EXAMPLE OF COMPUTER ASSISTED INSTRUCTION}

On the basis of the domestic and foreign research results, college students' composition and motion of bodies are studied, using Visual $\mathrm{C}^{++}$as the programming platform in Windows environment to design a set of analysis software of analytical and numerical methods based on mechanism simulation. This software can be used to build, modify and analyze the mechanism of class II and III, which can promote the research and innovation of the mechanism.

The characteristics and main functions of the software include:

- the mechanism of the connecting rod is studied, and further refined into eight component models. Meanwhile, two motion models are established by using vector method and constraint method.

- on the basis of the analysis of the motion of the components, the motion models of five kinds of class II rod groups and three kinds of class III rod groups are discussed, which can be used for reference in the study of the higher level pole group.

- A set of kinematic analysis and simulation software for linkage mechanism is designed. The software design idea of three layer structure is put forward, and the corresponding modules are established. The main interface of the software is shown in "Fig. 1".

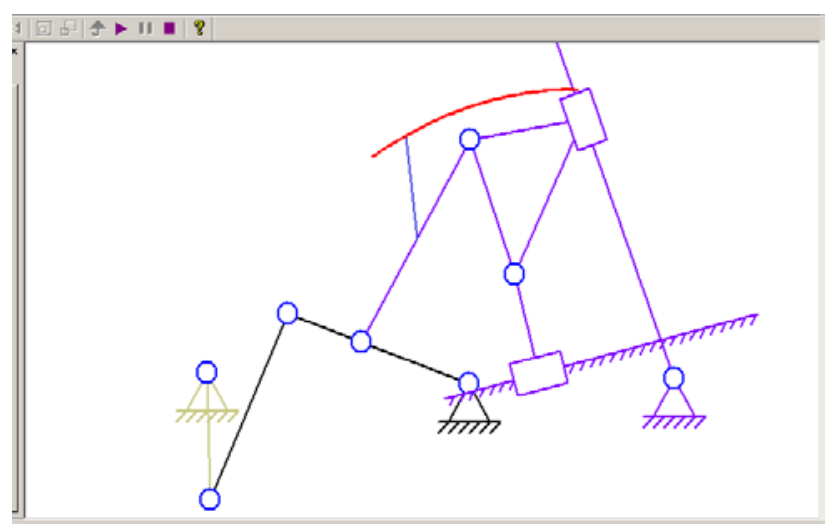

Fig. 1. Main interface of mechanism motion analysis and simulation software

For example, cam mechanism is a commonly used mechanism, which is widely used in machinery and instrumentation. Cam mechanism can accomplish expectant motive regular easily. in order to master the motion law of follower and the design of cam contour, the motion law of follower is analyzed and the theoretical outline and actual contour of cam are designed by MATLAB. Cam angle for rise, return and outer dwell all are 120 degrees. The rise motion of follower is sine acceleration motion, and the return motion of follower is uniform motion, which equation are shown in “TABLE I”. 
TABLE I. EQUATION OR FOLLOWER MOTION

\begin{tabular}{|c|l|}
\hline Follower travel & \multicolumn{1}{|c|}{ Follower motion Equation } \\
\hline \multirow{2}{*}{ Rise } & $s=h\left(\varphi / \varphi_{0}-\sin \left(2 \pi \varphi / \varphi_{0}\right) / 2 \pi\right)$ \\
& $v=h \omega\left(1-\cos \left(2 \pi \varphi / \varphi_{0}\right)\right) / \varphi_{0}$ \\
& $a=2 \pi h \omega^{2} \sin \left(2 \pi \varphi / \varphi_{0}\right) / \varphi_{0}^{2}$ \\
\hline Return & $s=h\left(\varphi_{0}-\varphi\right) / \varphi_{0}, v=-h \omega / \varphi_{0}, a=0$ \\
\hline
\end{tabular}

The calculation program is written by MATLAB, and the motion law curve and the cam contour curve are shown in "Fig. 2" and "Fig. 3" respectively.

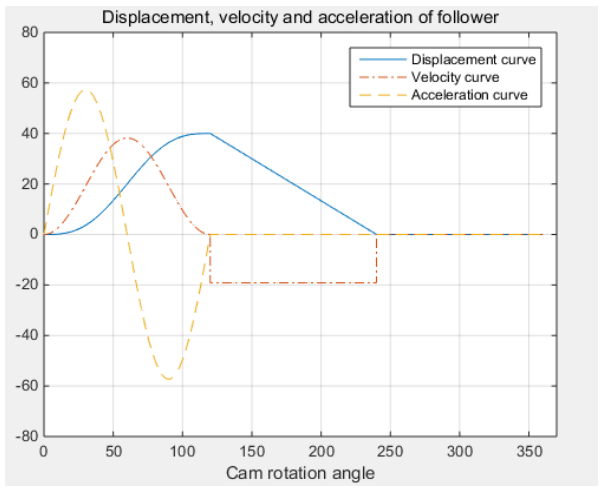

Fig. 2. The motion law curve

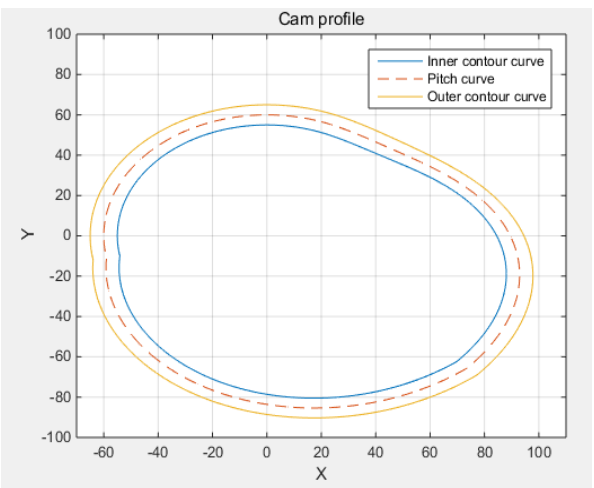

Fig. 3. The cam contour curve

\section{SUMMARY}

Computer assisted instruction can explain abstract theory through the chart analysis, 3D model, simulation animation, virtual reality and other means of full performance. Students consolidate the theoretical knowledge of mechanical principles, improve the software application ability and practical ability, and stimulate the enthusiasm of learning.

Computer aided instruction enriches the teaching methods and methods of mechanisms and machine theory course, and plays a very important role in the practice of this course. Practice shows that after the implementation of computer aided instruction in this course, the students' ability of calculation and analysis, software application and engineering practice have been greatly improved.

\section{ACKNOWLEDGMENT}

This research was financially supported by the teaching research project of Hubei Provincial Department of Education (No. 2016231).

\section{REFERENCES}

[1] Q.Chen, J.C.Zhu, and Y.J.Gong, "Research on applying computer software to the teaching of mechanisms and machine theory course", Journal of Hefei University of Technology (Social Sciences), vol. 25(01), pp. 145-148, April 2011. (In Chinese)

[2] F.Tao, "Application of aDAMS virtual prototype software in teaching theory of mechanism and machinery", Higher Education in Chemical Engineering, vol. 2, pp. 103-104, August 2005. (In Chinese)

[3] J.J.Zhang, Q.X.Huang, and L.N.Ma, "Improvement for dynamical simulation of four-bar linkage mechanism based on MATLAB/Simulink", Journal of Taiyuan University of Science and Technology, vol. 36 (05), pp. 390-396, December 2015. (In Chinese)

[4] Y.M.Xue, Y.X.Liu, "Visualization of Kineto-Elasto-Dynamics(KED) of planar linkage based on Matlab and VB", Mechnaical Science and Technology, vol. 4, pp. 502-504, May 2005. (In Chinese)

[5] H.G.Liu, J.Y.Kong, G.M.Zou,and Y.Hou, "Multiple application of computer technology in mechanical principle course design", China Metallurgical Education, vol. 4, pp. 42-43, May 2015. (In Chinese)

[6] J.Y.Kong, Y.Hou, J.T.Yang, H.Y.Liao,and J.Li, "Exploration and practice of the teaching mode of five transverse and five longitudinal matrix for the curriculum of mechanisms and machine theory”, Journal of Wuhan University of Science and Technology (social science edition), vol.11, pp. 101-104, January 2009. (In Chinese) 